\title{
Pollution and Its Control in Asbestos Milling Processes in India
}

\author{
Ashit Kumar MUKHERJEE ${ }^{1)}$, Raghavendra Rao RAJMOHAN ${ }^{1)}$, \\ Sudhir Kanhaiyalal DAVE ${ }^{2)}$, Bagalur Krishnamurthy RAJAN ${ }^{1)}$, \\ Yeshwanth KAKDE ${ }^{1)}$ and Srinivasapura Raghavendra RAO $^{1)}$
}

1) Regional Occupational Health Centre (S), Bangalore Medical College Campus, Library Information Block, Bangalore-560002

2) National Institute of Occupational Health, Ahmedabad-380016

(Received October 19, 1993 and in revised form November 21, 1995)

\begin{abstract}
An intervention study has been conducted in chrysotile asbestos milling processes with an interval of one year. The 'Membrane Filter Method' adopted in the former study for fiber concentration estimation has been followed in the present study, to estimate the environmental samples under the same experimental conditions. Though very high fiber levels compared to the prescribed permissible limit in India, have also been obtained in this study, a general reduction trend in the values of mills common to the both studies are observed. A further suitable control measure has been recommended in the paper to reduce fiber levels in the milling processes.
\end{abstract}

Key words: Chrysotile asbestos — Milling operation - Fiber level — Control device

\section{INTRODUCTION}

The potential health risk of asbestos are well documented. It is evident from the available literature that all types of asbestos, though they vary in degree of potency, are capable to induce malignancy ${ }^{1)}$. A higher level of occupational exposure to chrysotile asbestos should also be considered as a serious health concern. The prevailing environmental conditions at the chrysotile milling operations of Andhra Pradesh in India have been found extremely hazardous by the authors in a survey conducted during the year 19892). It was reported in the study that the workers were exposed to very high concentration of fibers, $30 \%$ of which had length more than $10 \mu \mathrm{m}$ and majority were of breadth, $1.6 \mu \mathrm{m}$ and below. Examination of environmental samples under a scanning electron microscope indicated

Address reprint requests to A. K. Mukherjee, Regional Occupational Health Centre (Eastern), 3, Dr. M. Ishaque Road (Kyd Street), Calcutta-700016 (INDIA). Tel: 29-5314, 29-4572; Fax:

91-33-29-5314 
the presence of tremolite as has been reported elsewhere in Canadian chrysotile ${ }^{3)}$. As an immediate suggestive measure after this study, the authors stressed on the adoption of control measure along with health education programme to create awareness of the hazardous character of asbestos dust, good house-keeping, personal hygiene and safe work-practice. The management of the mills attempted some scattered measures to bring down fiber levels in mills immediately after the study.

A second environmental survey was undertaken by the authors in 1990, exactly after one year with a purpose to observe the improvement in the fiber levels at processing areas. This paper deals with the results of fiber measurements in the intervention study particularly on those of common mills to both the studies. Lines of discussion on the control measures adopted and its suitability in the present set up of the processing machineries are also included in the paper.

It has been described earlier that in conventional type millings the asbestos bearing rocks are fiberized into a finer form by several processing stages such as pulverization, decortication, screen gradation, and manual grading. The present study, along with the mills of the conventional type, also included a mechanised milling plant where the processes are interlinked in a sequence and entirely ducted to segregate the plant from general mill-air. There are two stages of fiberization to increase fiber fineness followed by screens to concentrate fibers according to its length. Devices such as elevators, air-lift, and screw conveyors are attached to transfer the materials under process from one stage to the other and also to separate the rocky mass from fibrous. Finally, fine fibers are separated from the coarse material by cyclone collector. The man power requirement in case of the mechanised plant is much less compared to those in conventional type mills.

There are several studies reported on the exposure and health risk of workers occupationally exposed to asbestos ${ }^{4-7}$. In a study conducted in British Columbia, the reported fiber levels in the mill air varied from 0.7 to 88 fiber per $\mathrm{cm}^{38)}$. Another study conducted in Western Australia ${ }^{9)}$ in 1988 reported the concentration up to 100 fibers per $\mathrm{cm}^{3}$ in bagging area of the mill. A study conducted in Canadian asbestos mines and millings during 1973 reported mill-airfiber levels to vary between 1.1-189 fiber per $\mathrm{cm}^{3}{ }^{10}$. But reports on the occupational hazards and its control in developing countries are lacking. The milling operations in developed countries are mostly mechanised and are different from the conventional milling. As switching over from conventional to automated plant in India involves a huge economic constrain, control measures effective to the existing set up at reasonable costs are always required.

\section{Materials And Methods}

The intervention study was undertaken during 1990 in six asbestos mills, A, B, $\mathrm{C}, \mathrm{D}, \mathrm{E}$ and $\mathrm{F}$ situated in the neighbouring areas of Andhra Pradesh (India). Out 
of these, Mill $\mathrm{F}$ is only mechanised and the rest are of conventional type. Mills A, B, C and D were covered in both the surveys conducted during September of 1989 and 1990. The research team involved in the present study, including the hygienists and microscopists, were same as earlier. The reference method of the Bureau of Indian Standard (BIS) ${ }^{11)}$ for determination of air borne asbestos fiber concentrations at work-places by light microscopy (Membrane filter method) was also used in this study like the earlier (BIS, 1986).

A total of 163 short-term environmental samples were collected at a distance of 2-4 ft. from the processes over a period 5-10 minutes at the rate of 1 litre per minute on membrane filter (Millipore AA, $0.8 \mu \mathrm{m}$ pore size, $25 \mathrm{~mm}$ diameter, Massachusetts, U.S.A.) by using personal sampler (AFC 123, Casella, London). Acetone-triacetin technique was adopted for sample preparation as done in the previous study. The same phase contrast optical microscope equipped with an automatic photographic attachment (Olympus, Model BH-2, Tokyo) and incorporated with the "Walton and Beckett" graticule (Edinburgh) was used at a magnification of 400x for fiber counting ${ }^{2}$. The experimental conditions and the criteria of fiber counting were same for both the studies (i.e., length more than $5 \mu \mathrm{m}$; diameter less than $3 \mu \mathrm{m}$ and length to diameter ratio greater than 3:1). All care was taken to minimise the possible errors of sampling and counting fibers as per recommendations in the method (BIS, 1986) ${ }^{11}$. The fiber counting was performed in the same specified laboratory.

\section{RESULTS}

The process-wise mean and range of fiber levels obtained during September, 1990 in the mills, A, B, C, D, E (conventional type) and F (mechanised type) are presented respectively in Tables 1 and 2 as the conditions are different. A typical dust field view of a membrane sample under a phase contrast optical microscope at magnification of $400 \mathrm{x}$ is shown in Figure 1. Bar diagrams, shown in Figures 2 and 3 are respectively the fiber levels at different processes of the mills, A, B, C and D combinedly and individually for the present study as well as that conducted by the authors in $1989^{2}$. Since fiber concentrations, presented in the paper, represent values of short-term sampling at close proximity of the processes, the highest values may also be considered as peak exposure levels for those engaged adjacent to the processes.

\section{Discussion}

The average fiber concentration levels obtained in the study (Table 1) have been found to be higher than the Indian Standard for chrysotile asbestos of 2 fibers per $\mathrm{cm}^{3}{ }^{12)}$ and also that adopted by many developed and developing countries of the world $^{13)}$. The highest fiber level recorded in Mill $\mathrm{E}$ at the decorticator is about 
Table 1. Average and range of fiber concentrations (fbr./ml) in chrysotile asbestos milling processes for five mills, 1990. Method: Short-term samples.

\begin{tabular}{|c|c|c|c|c|c|c|}
\hline $\begin{array}{l}\text { SL. } \\
\text { No. }\end{array}$ & Process & MILL-A & MILL-B & MILL-C & MILL-D & MILL-E \\
\hline 1. & Jaw Crusher & $\begin{array}{l}12.2(5) \\
5.5-21.9\end{array}$ & $*$ & $*$ & $*$ & $*$ \\
\hline 2. & Pulverizer & $\begin{array}{l}11.8(4) \\
8.5-19.3\end{array}$ & * & $*$ & * & $*$ \\
\hline 3. & Lime Mix & $*$ & $\begin{array}{c}5.4(5) \\
2.5-10.5\end{array}$ & $\begin{array}{l}11.0(6) \\
2.9-23.4\end{array}$ & $\begin{array}{c}6.5(5) \\
4.0-8.2\end{array}$ & $\begin{array}{c}16.9(4) \\
8.6-23.1\end{array}$ \\
\hline 4. & Huller & $*$ & $*$ & $\begin{array}{l}12.2(5) \\
4.8-18.2\end{array}$ & $*$ & $*$ \\
\hline 5. & Primary Eccentric Screen & $\begin{array}{l}10.0(5) \\
5.6-16.7\end{array}$ & $\begin{array}{c}7.1(5) \\
2.0-11.1\end{array}$ & $\begin{array}{c}8.3(4) \\
3.7-13.6\end{array}$ & $\begin{array}{l}11.5(5) \\
6.2-15.3\end{array}$ & $\begin{array}{c}11.3(4) \\
8.0-17.6\end{array}$ \\
\hline 6. & Decorticator & $\begin{array}{c}6.0(5) \\
3.9-9.5\end{array}$ & $\begin{array}{c}7.9(5) \\
4.3-11.7\end{array}$ & $\begin{array}{l}11.5(9) \\
3.1-17.4\end{array}$ & $\begin{array}{l}11.5(5) \\
6.2-26.7\end{array}$ & $\begin{array}{l}24.9(5) \\
7.5-67.2\end{array}$ \\
\hline 7. & $\begin{array}{l}\text { Fiber Room: } \\
\text { a) Before work }\end{array}$ & $3.6(1)$ & - & - & $\begin{array}{c}5.6(2) \\
4.7-6.4\end{array}$ & $\begin{array}{l}7.6(2) \\
6.7-8.5\end{array}$ \\
\hline & b) During work & $\begin{array}{l}12.2(5) \\
7.6-16.8\end{array}$ & $\begin{array}{c}5.9(5) \\
4.5-7.1\end{array}$ & $\begin{array}{c}8.1(5) \\
1.4-15.1\end{array}$ & $\begin{array}{l}13.9(2) \\
9.0-18.7\end{array}$ & $\begin{array}{l}29.3(3) \\
9.6-55.1\end{array}$ \\
\hline 8. & Final Eccentric Screen & $\begin{array}{l}27.5(7) \\
6.3-48.5\end{array}$ & $*$ & $\begin{array}{l}14.2(5) \\
8.0-20.1\end{array}$ & $*$ & $*$ \\
\hline 9. & Manual Screen & $\begin{array}{l}11.6(5) \\
4.6-21.9\end{array}$ & $*$ & $\begin{array}{l}12.4(5) \\
5.5-25.2\end{array}$ & $*$ & $\begin{array}{c}23.2(5) \\
14.7-34.3\end{array}$ \\
\hline
\end{tabular}

Figures in the parenthesis indicate number of samples.

* Process does not exist in the mill.

Table 2. Average and range of fiber concentrations (fbr./ml) in mechanised chrysotile asbestos milling process. Method: Short-term samples.

\begin{tabular}{lllcc}
\hline & & & \multicolumn{2}{c}{ MILL-F } \\
\cline { 4 - 4 } No. & Sampling locations & $\mathbf{n}$ & Average & Range \\
\hline 1. & Feeding Point & 5 & 16.2 & $8.0-21.5$ \\
2. & Screen-I & 4 & 11.4 & $9.5-15.3$ \\
3. & Screw Conveyor & 4 & 19.4 & $11.7-31.6$ \\
4. & Screen-II & 3 & 18.8 & $11.5-23.0$ \\
5. & Cyclone-I & 3 & 14.6 & $12.8-16.8$ \\
6. & Cyclone-II & 5 & 12.1 & $3.7-19.4$ \\
\hline
\end{tabular}

$\mathrm{n}=$ No. of samples. 


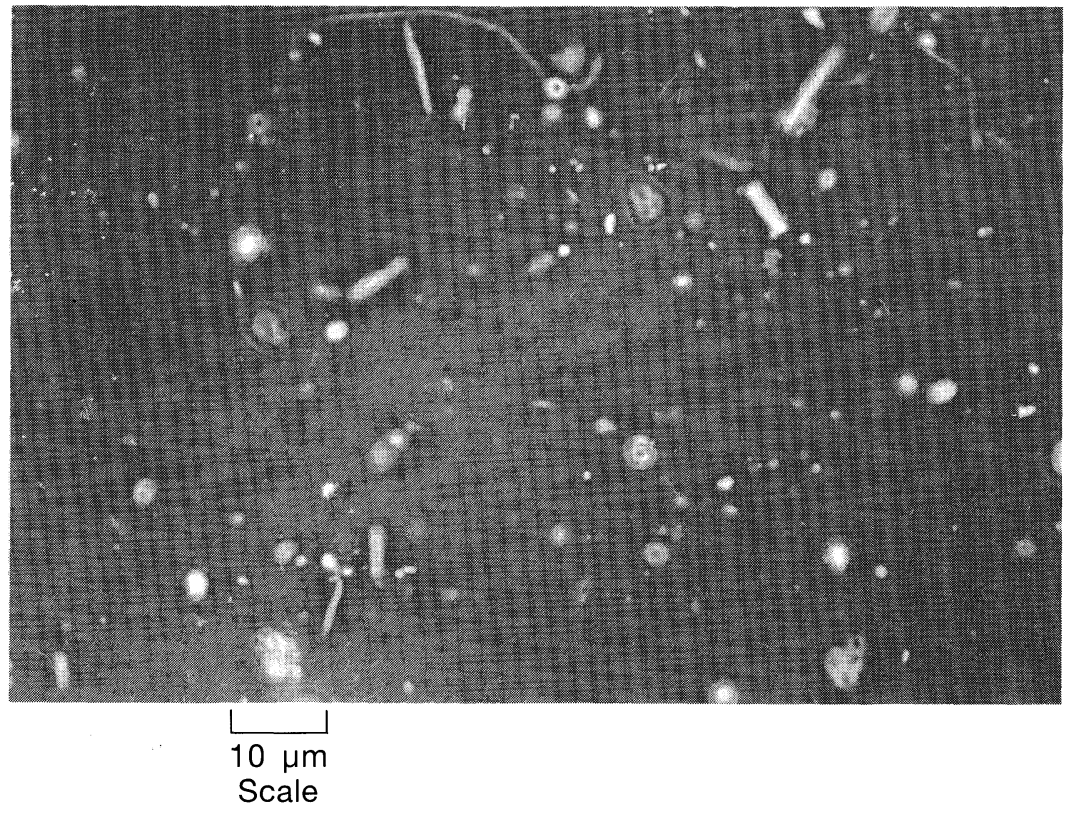

Fig. 1. A typical dust field view of the environmental sample under phase contrast optical microscope at $400 \mathrm{X}$, collected from the mill.

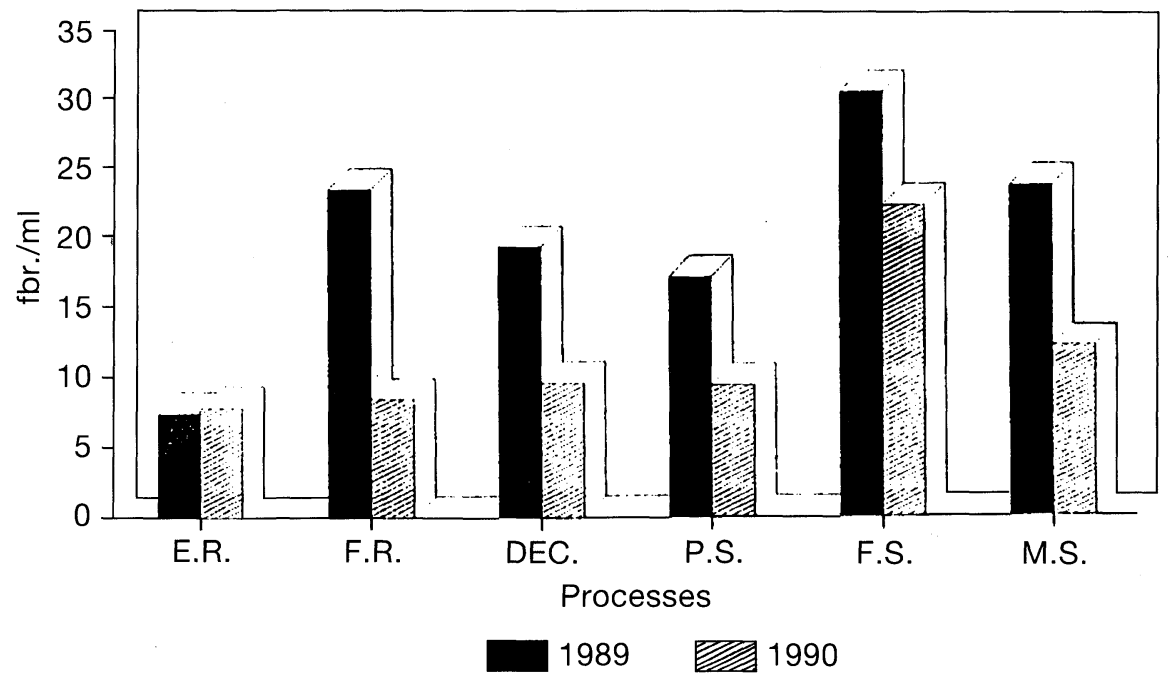

E.R.-Edge Runner; F.R.-Fiber Room; DEC-Decoticator

P.S.-Primary Screen; F.S.-Final Screen; M.S.-Manual Screen

Fig. 2. Fiber levels in different processes of the mills common to both the studies. 

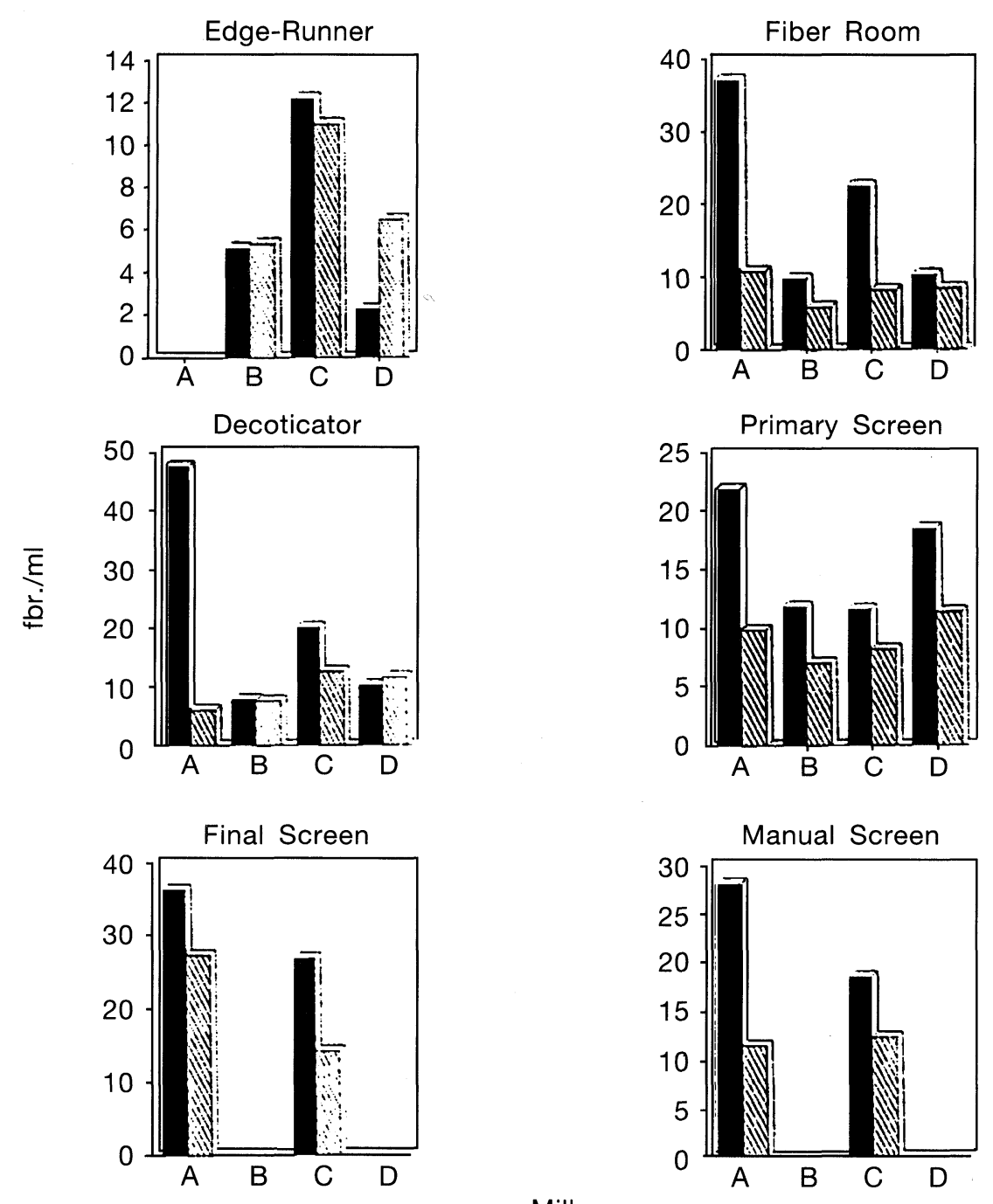

Mills 1989

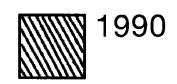

Fig. 3. Process wise fiber levels in four mills for two different years.

33 times higher than the prescribed threshold limit. In the present study, Mill E showed the highest fiber concentrations for the processes common among all the mills in Table 1. When the results in Table 1 are compared to those of our earlier study $^{2)}$ to observe the prevailing condition with respect to fiber levels in mills, a general reduction trend is found in the present study for almost all the processes 
of the four mills (A, B, C, D). This trend may be more clearly seen from the bar diagrams shown in Figures 2 and 3 respectively for milling processes combinedly and individually. A few cases, where higher results have been found in the later study, may be accounted because no improvement was made over earlier conditions but the ventilations in the areas were influenced directly by outside air. The decreasing trend observed in the fiber concentration levels may be attributed to the measures adopted after the first study as well as the much more careful work practice adopted by the workers.

It is evident from Table 2 that the fiber concentration levels at different locations of the mechanised Mill $\mathrm{F}$ are also higher than the prescribed threshold limit. Though in the mechanised mill, the processes are well segregated from general mill air and ducted all through, the results show there are considerable fiber emission in the mill environment. The mean fiber concentration levels at different processing points have not been found to vary much. The highest value recorded at the screw conveyor is attributable to some leakage in the duct.

\section{Exposure Control in Asbestos Milling:}

During the course of the first study, hardly any control measure were noticed in the mills. The manual operations like lump-breaking, material shifting, material feeding and collection, and sorting were found to be undertaken without protective measures. The handling of asbestos by the workers was noticed much more harsh and not at all safe.

During the second study, however, some remarkable changes were noticed. Workers were found with respiratory masks and uniforms during work. Material handlings were more careful. General house-keeping in the mills was found to be improved. Some re-arrangements in positions of processes within the mill were also noticed. The processes like edge runners and screens in most cases were found covered with metal hoods to get the evolved fibers settled within the processes. In some cases, extraction hoods were placed above screens though it was not effective. It was also found that a duct from the feeding hopper to the blower of decorticator was drawn with an idea to extract the generated dust at the feeding point. All these measures attempted in the mills were found not effective enough to bring down the fiber level below threshold limit by the Indian Standard. A proper control device must therefore be adopted in these mills.

\section{Recommended Control Measures:}

To ensure the control of workers' exposure to asbestos in the mills, house keeping, rigorous personal hygiene with clothing changes and showering after the work shift etc., are recommended to be made mandatory. Vacuum cleaners with high efficiency particulate air filter should always be used instead of dry sweeping ${ }^{14)}$. In the design of a most effective dust extraction hood, it is essential to 
minimise the capture distance (i.e., distance between the point of dust generation to point of collection) and to provide sufficient air exhaust rate ${ }^{15)}$.

A control device comprised of 'Hood-Filter-Fan' is recommended for emission control for the asbestos mills surveyed in this study. A total enclosure of the processes wherever possible such as Jaw crusher, lime mix, eccentric screens (primary and final) or effective local extraction hoods (in case of pulveriser, huller, decorticator and manual screen) with minimum capture distance and adequate exhaust rate, attached with a fabric filter system, small enough to fit into a room to arrest even sub-micronic size fibers and a fan as an air drawing device at the last of the line are required to be installed to control the emission from conventional milling operations. The fiber room should be made leak proof by sealing the openings to stop diffusion of fibers in the mill air. The manual operations must be carried out with great care and proper protective equipments.

In case of mechanised plant, the entire duct should be kept at negative pressure so that the fibers, instead of being emitted, are kept inside the system. The plant should be made perfectly leak proof by sealing the duct joints, elbow of the ducts etc. to control the emission effectively. 
3) Churg A, Wiggs B, Depaoli L, Kampe B, Stevens B. Lung asbestos content in chrysotile workers with mesothelioma. Am Rev Resp Dis 1984; 130: 1042-5.

4) Dement JM, Harris RL, Symons MJ, Shy CM. Exposure and mortality among chrysotile asbestos workers. Part-II; Mortality. Am J Ind Med 1983; 4: 421-33.

5) Langer AM, Mc Caughey WT. Mesothelioma in a brake repair worker. Lancet 1982; 8307: 11013.

6) Huncharek M. Chrysotile asbestos exposure and mesothelioma. Br J Ind Med 1987; 44: 287 8.

7) McDonald JC, Becklake MR, Gibbs GW, McDonald AD, Rossiter CE. The health of chrysotile asbestos mine and mill workers of Quebec. Arch Environ Health 1974; 28: 61-8.

8) Enarson DA, Valerie Embree, Lonia Maclean, Grzybowski S. Respiratory health in chrysotile asbestos miners in British Columbia-a longitudinal study. Br J Ind Med 1988; 45: 459-63.

9) Armstrong BK, De Klerk NH, Musk AW, Hobbs MST. Mortality in miners and millers of crocidolite in Western Australia. Br J Ind Med 1988; 45: 5-13.

10) Selikoff IJ, DHK Lee. Asbestos and Disease. New York: Academic Press 1978, 107.

11) Bureau of Indian Standards IS-11450, 1986.

12) International Labour Office, Geneva. Safety in the use of asbestos. 1984, 94.

13) World Health Organisation, Geneva (1989). Occupational Exposure limit for asbestos. Apr. WHO/ $\mathrm{OCH} / 89.1: 10-1$.

14) Patty's Industrial Hygiene and Toxicology, General Principles. Vol. I, 1978, 1183.

15) Alden J. Design of Industrial Exhaust Systems. New York: Industrial Press 4th Ed., 1970. 